\title{
Foreshocks and Aftershocks of the Great 1857 California Earthquake
}

\author{
by Aron J. Meltzner and David J. Wald
}

\begin{abstract}
The San Andreas fault is the longest fault in California and one of the longest strike-slip faults anywhere in the world, yet we know little about many aspects of its behavior before, during, and after large earthquakes. We conducted a study to locate and to estimate magnitudes for the largest foreshocks and aftershocks of the $1857 M 7.9$ Fort Tejon earthquake on the central and southern segments of the fault. We began by searching archived first-hand accounts from 1857 through 1862 , by grouping felt reports temporally, and by assigning modified Mercalli intensities to each site. We then used a modified form of the grid-search algorithm of Bakun and Wentworth, derived from empirical analysis of modern earthquakes, to find the location and magnitude most consistent with the assigned intensities for each of the largest events. The result confirms a conclusion of Sieh that at least two foreshocks ("dawn" and "sunrise") located on or near the Parkfield segment of the San Andreas fault preceded the mainshock. We estimate their magnitudes to be $M$ $\approx 6.1$ and $M \approx 5.6$, respectively. The aftershock rate was below average but within one standard deviation of the number of aftershocks expected based on statistics of modern southern California mainshock-aftershock sequences. The aftershocks included two significant events during the first eight days of the sequence, with magnitudes $M \approx 6.25$ and $M \approx 6.7$, near the southern half of the rupture; later aftershocks included a $M \approx 6$ event near San Bernardino in December 1858 and a $M \approx 6.3$ event near the Parkfield segment in April 1860. From earthquake logs at Fort Tejon, we conclude that the aftershock sequence lasted a minimum of 3.75 years.
\end{abstract}

\section{Introduction}

Two large earthquakes have occurred during historic times (in 1857 and 1906) on the San Andreas Fault (SAF), although little is known about foreshocks and aftershocks of those events; in particular, little is known about foreshocks and aftershocks of the $M 7.9$ Fort Tejon (FT) earthquake, which occurred at 8:24 PST on the morning of 9 January 1857 (see Figure 1 for location). Sieh (1978b) gathered historic accounts of the foreshocks and the earliest aftershocks (within the first few weeks of the sequence) of the 1857 FT event. He compared the geographical distributions of intensities from the two largest foreshocks ("dawn" and "sunrise," roughly two and one hours, respectively, prior to the mainshock; earthquake names are from Sieh, 1978b) and from two aftershocks (night of 9 January and afternoon of 16 January 1857) to those of modern earthquakes, and he used intuition to locate the epicenters (to a first-order approximation) and assign approximate magnitudes.

More recently, Bakun and Wentworth (1997) developed an algorithm for constraining both epicenter and magnitude for early California earthquakes in cases where few observations exist and where the felt area (or area of a particular intensity) is difficult to ascertain. In addition, critical data has recently been uncovered in several forms, one of which being earthquake logs kept at Fort Tejon from January 1857 through May 1861. In light of the new algorithm and new data, we chose to reevaluate the largest foreshocks and aftershocks of the 1857 FT earthquake and to extend the search for aftershocks through April 1862, more than five years after the mainshock. We published a USGS Open-File Report (OFR) (Meltzner and Wald, 1998) that contains our data, a detailed description of our analysis, and a catalogue of reported earthquakes in southern and central California for the time period January 1857 to April 1862; this article is essentially a synopsis of the OFR, to which we will refer on occasion.

\section{Methodology}

We combined data from preexisting catalogues and papers with felt reports from primary sources to prepare our earthquake catalogue for January 1857 through April 1862. After cataloguing the events, we associated felt reports temporally and "red-tagged" any aftershocks if either (a) seismic shaking was reported in two or more places at roughly the same time, or (b) shaking was unusually strong or damage was done in at least one location. For the larger events, we assigned modified Mercalli intensities (MMI) to each site 


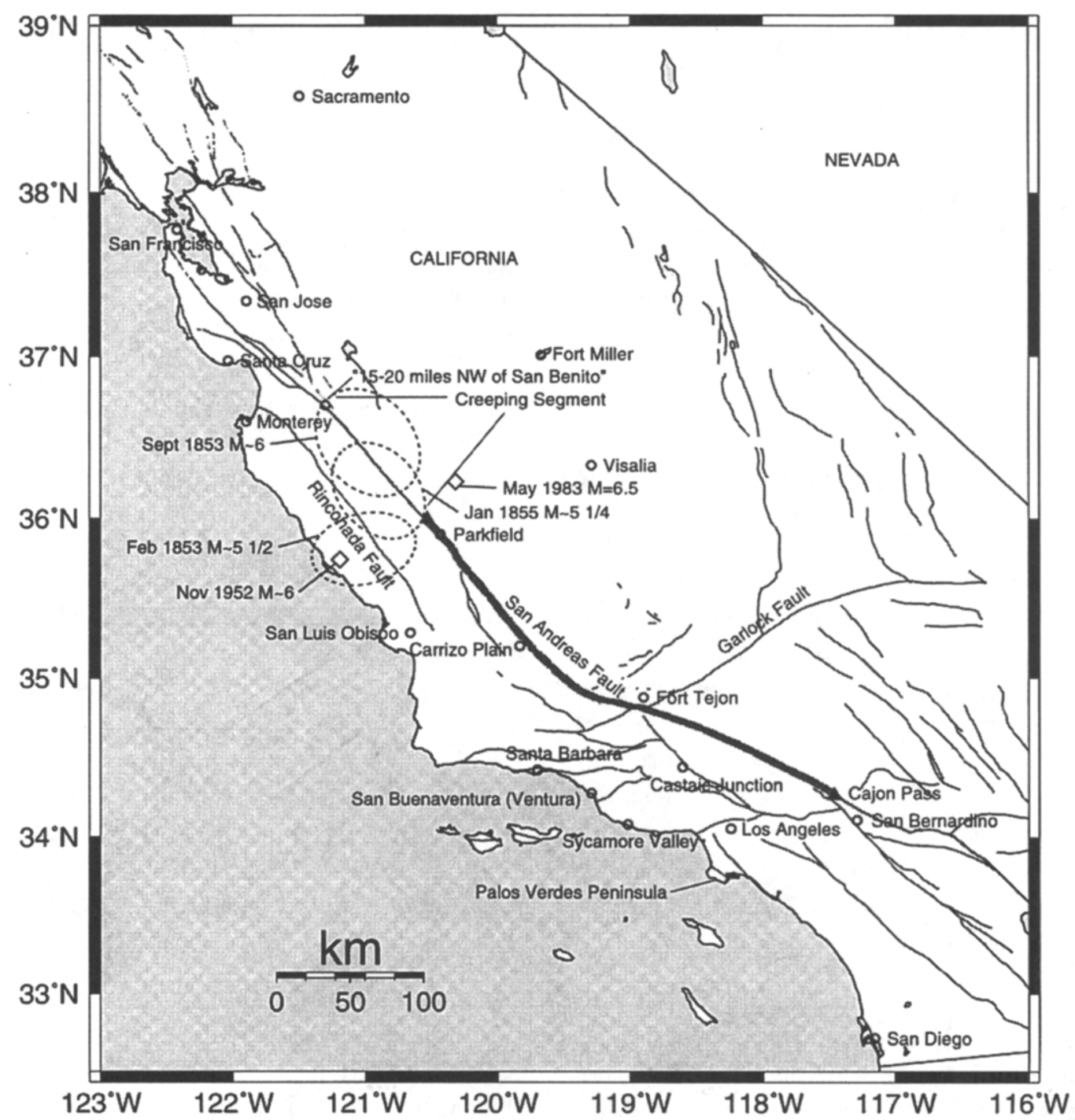

Figure 1. Location Map, showing the 1857 mainshock fault rupture (thick line), locations of observations used in this study, and other locations mentioned in this paper (locations for San Benito and Sycamore Valley are from Agnew and Sieh [1978]). The approximate locations for three earthquakes (February 1853, September 1853, January 1855) mentioned by Toppozada and Borchardt (1998) are denoted by dashed ellipses; the locations for the 1952 Bryson earthquake and the 1983 Coalinga earthquake (Ellsworth, 1990) are denoted by diamonds.

based on descriptions of damage or reports of felt shaking. Then, for events for which we had at least three intensity data points, we applied a grid-search algorithm based on, but slightly modified from, that of Bakun and Wentworth (1997); specifically, it was lacking site corrections and a distance weighting function they included (see the Appendix for further discussion of modifications we made for our analysis).

To summarize, we computed the best magnitude, $M_{l}$, and the total rms error between observed and estimated intensities, $\mathrm{rms}\left[M_{I}\right]$, for that magnitude for a grid of potential epicenters in the felt region. Here, $M_{I}$ is the mean of $M_{i}$, and

$$
M_{i}=\left[\left(\mathrm{MMI}_{i}+3.29+0.0206 * \Delta_{i}\right) / 1.68\right] \text {, }
$$

where $\Delta_{i}$ is the distance (in $\mathrm{km}$ ) of observation $\mathrm{MMI}_{i}$ from the assumed grid point. The location of the earthquake is bounded by contours of

$$
\operatorname{rms}\left[M_{I}\right]=\left[\operatorname{rms}\left(M_{I}-M_{i}\right)-\operatorname{rms}_{0}\left(M_{I}-M_{i}\right)\right],
$$

where $\mathrm{rms}_{0}\left(M_{I}-M_{i}\right)$ is the minimum rms over the grid of potential epicenters. The point associated with the minimum rms is the "intensity center." These rms error contours appear as dotted black lines in Figure 2-6. 


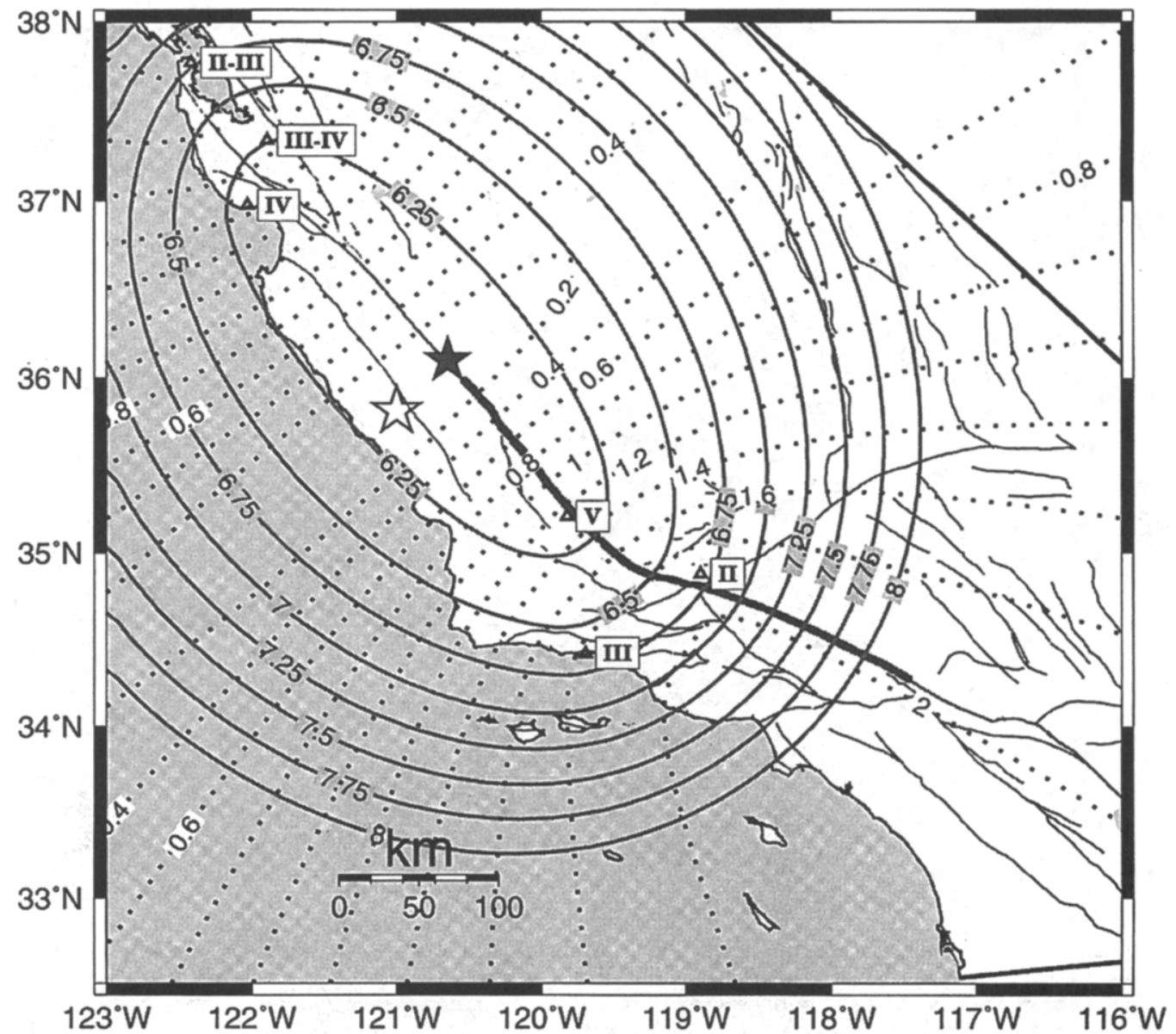

Figure 2. Map of rms contours and magnitude contours for the dawn foreshock. Thin lines are faults; the thick line is the extent of the 1857 rupture; triangles are stations with intensity data (possible MMI values are indicated in roman numerals); dotted contours are rms contours; the clear star is the location corresponding to the intensity center; the filled star is the location of the least rms value among points on the SAF; and the solid contours are magnitude contours. See text for details.

The level of confidence can be assigned to each contour based on the number of intensity observations. The rms contours corresponding to the $95 \%, 90 \%, 80 \%, 67 \%$, and $50 \%$ confidence levels, for various quantities of MMI observations, are given in Table 1. The "best" epicenter is assigned based on both the lowest rms error contours and tectonic considerations; that is, we look for tectonically attractive locations in light of the rms contours.

The magnitude associated with a particular (potential) epicenter can be read from the magnitude contours for the grid, which appear as solid gray lines in Figures 2-6. $M_{I}$ at tectonically attractive potential epicenters within the appropriate confidence-level contours are the best estimates of magnitude for those epicenters.

\section{Sources of Error and Uncertainty in Magnitude}

There are two possible sources of error in magnitude, and each must be assessed separately. The first potential for error arises from uncertainties in the earthquake's location (which are inherent in Bakun and Wentworth's algorithm) and from the possibility of an observation coming from within a geographic pocket of anomalously high or low intensity; this first potential for error is accounted for and assessed statistically by Bakun and Wentworth, with uncertainty in $M_{I}$ appropriate for the different confidence levels and quantities of MMI observations listed in Table 2.

The second potential source of error is more unique to our situation. Because many of the first-hand reports we are dealing with are vague (and in some cases have only a oneword description such as "severe" or "slight"), in some cases we are not completely certain of intensity at a particular location. In their algorithm, Bakun and Wentworth assumed the intensity for each location was known unambiguously (even if it may have been anomalous geographically) and did not consider uncertainties in intensities. We must therefore address the question: if our assignment of intensity was skewed from the "true value"-either by a bad report or by 


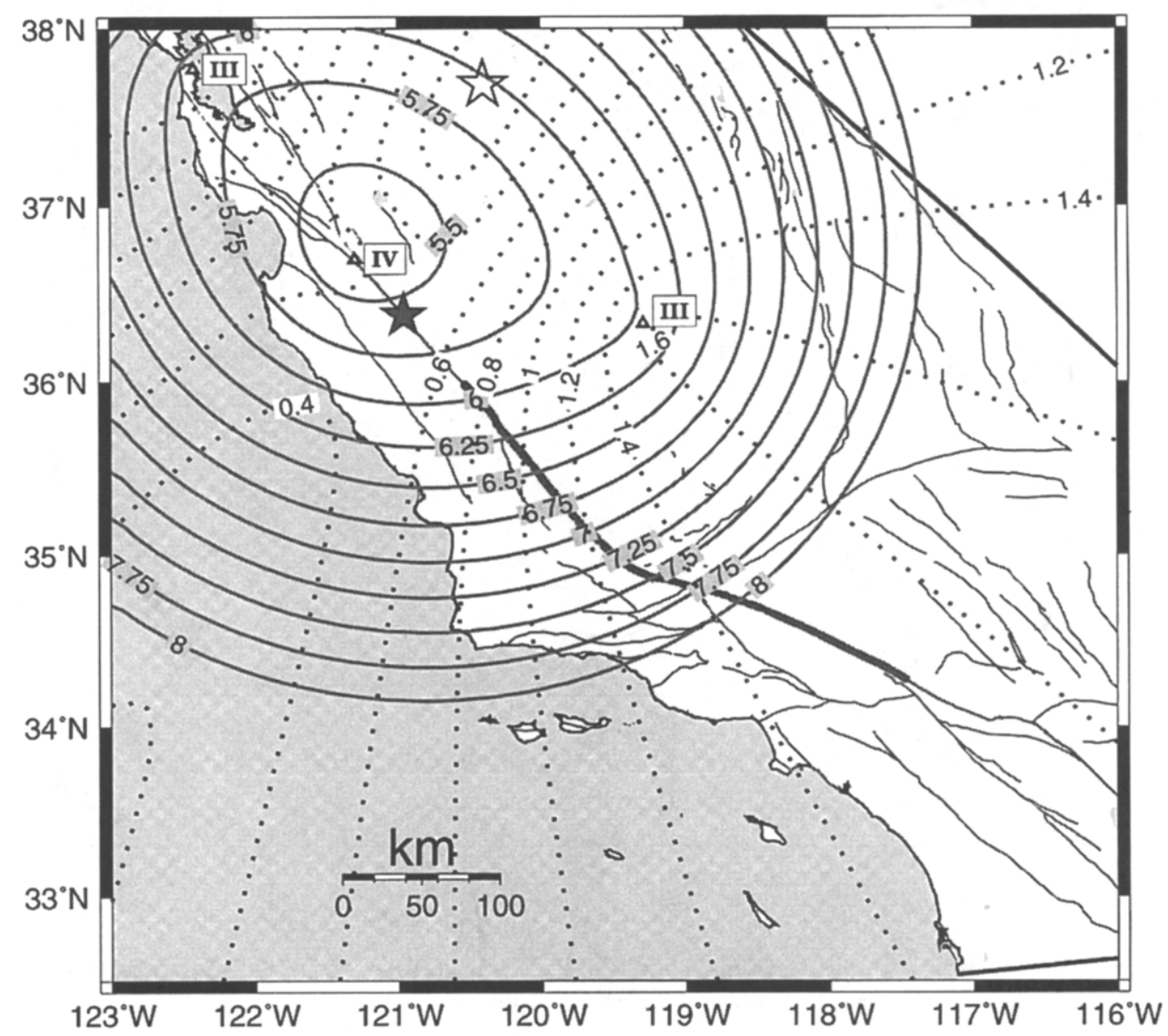

Figure 3. Map of rms contours and magnitude contours for the sunrise foreshock. Thin lines are faults; the thick line is the extent of the 1857 rupture; triangles are stations with intensity data (possible MMI values are indicated in roman numerals); dotted contours are rms contours; the clear star is the location corresponding to the intensity center; the filled star is the location of the least rms value among points on the SAF; and the solid contours are magnitude contours. See text for details.

our misinterpretation of a (vague) report-then to what extent might our results be thrown off?

The best way to answer this question is to accommodate all possibilities. Whenever an intensity value was in question, we assigned a range of values so that all possibilities were included. We then plotted different versions of each map (only one representative version for each event is included in this article) so that we had one version for each of the possible combinations of potential intensities, and we noted the extent to which location and magnitude might be affected by a bad assignment of intensity at any particular location. As before, we chose the most tectonically attractive epicenter within an appropriate region, although in this case, a range of possible magnitudes associated with that epicenter (allowing for uncertainties in intensity) was manually determined by reading the magnitude at that location on each version of the map.

Finally, the two sources of error must be combined and the overall uncertainty must be determined. We took the range of possible magnitudes that arose from the intensity uncertainties, and we converted that range into a mean and magnitude uncertainty (e.g., a range of 6.1 to 6.5 became $6.3 \pm 0.2$ ). We then added an additional uncertainty (to allow for the uncertainty in epicenter and the possibility of geographically anomalous intensities) as determined in Table 2 for the appropriate number of intensity data points. For this article we added an additional magnitude error of \pm 0.2 (valid for 3 to 6 observations at 50\% confidence; see Table 2 ) to the error associated with the uncertainty in intensities. Although this is not a completely rigorous statistical approach, it gives us reasonable estimates of the overall error at $50 \%$ confidence.

\section{Largest Foreshocks}

Sieh (1978b) identified a swarm of small foreshocks scattered across much of northern and central California in the 9-hr period preceding the 8:24 a.m. mainshock, as well 


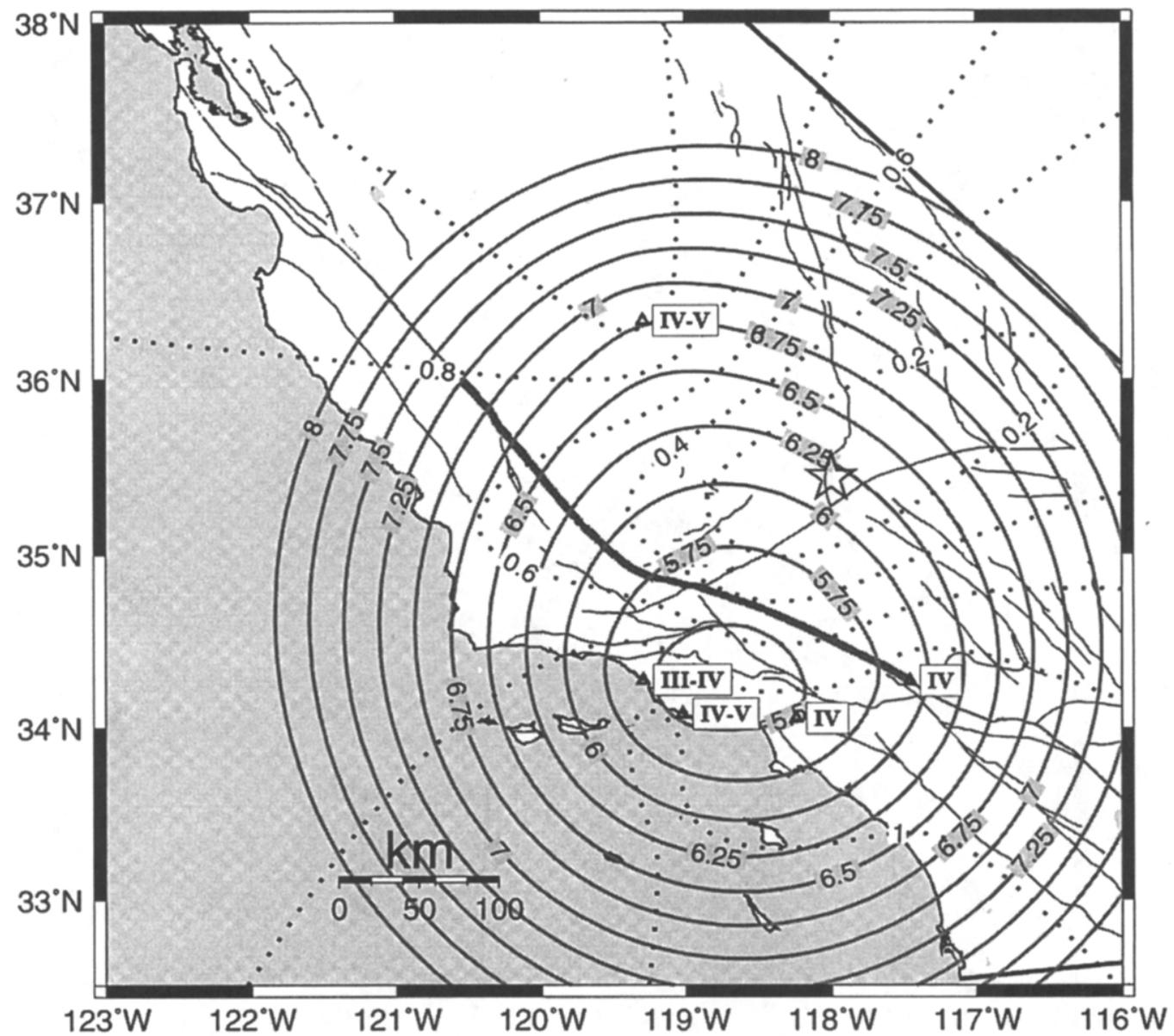

Figure 4. Map of ims contours and magnitude contours for the 9 January 1857, 11 p.m. aftershock. Thin lines are faults; the thick line is the extent of the 1857 rupture; triangles are stations with intensity data (possible MMI values are indicated in roman numerals); dotted contours are rms contours; the clear star is the location corresponding to the intensity center; and the solid contours are magnitude contours. See text for details.

as the more widely felt dawn and sunrise foreshocks centered in a region northwest of Parkfield, California; he estimated locations and magnitudes for the two widely felt foreshocks. Below we take another look at these two foreshocks, using the algorithm modified from Bakun and Wentworth (1997), although the vague nature of the reports of the smaller foreshocks prevents us from further analyzing any of them.

\section{Dawn Foreshock}

A map showing the results of the grid-search algorithm for the dawn foreshock is given as Figure 2. The location of the point of least rms error (the intensity center) implies a location near that of the $1952 \mathrm{M} 6.0$ Bryson earthquake; the 1952 earthquake might have been produced by movement on the Nacimiento fault (Richter, 1969), although the highest intensities were centered on the Rinconada fault (Sieh, 1978b). (The Nacimiento fault is roughly parallel to and about $20 \mathrm{~km}$ southwest of the Rinconada fault in central
California; see Fig. 1 for location.) The rms error contours are elongated in a direction roughly perpendicular to the SAF and to the coastline, although this elongation occurs naturally as a result of the population distribution: there are observation points that bound the rms error contours from the northwest and from the southeast, but there are no data points to bound the rms error values from the northeast or southwest. In addition to the Bryson location, the $50 \%$ confidence interval (which, for 6 observations, corresponds to the area within an rms error contour of $\sim 0.11$ ) on the map in Figure 2 includes the presumed northwestern extent of the 1857 mainshock rupture and $\sim 35 \mathrm{~km}$ of the SAF to the northwest (equivalently, a stretch of the SAF from $\sim 10$ to $\sim 50 \mathrm{~km}$ northwest of Parkfield). Note that several historical records indicate that the rupture may have extended up to 50 $\mathrm{km}$ beyond the northwestern limit indicated in Figures 1-7 (Sieh, 1978a). The 50\% confidence interval also includes the epicenter of the $1983 M 6.7$ Coalinga earthquake.

Varying the intensity values within our bounds of un- 


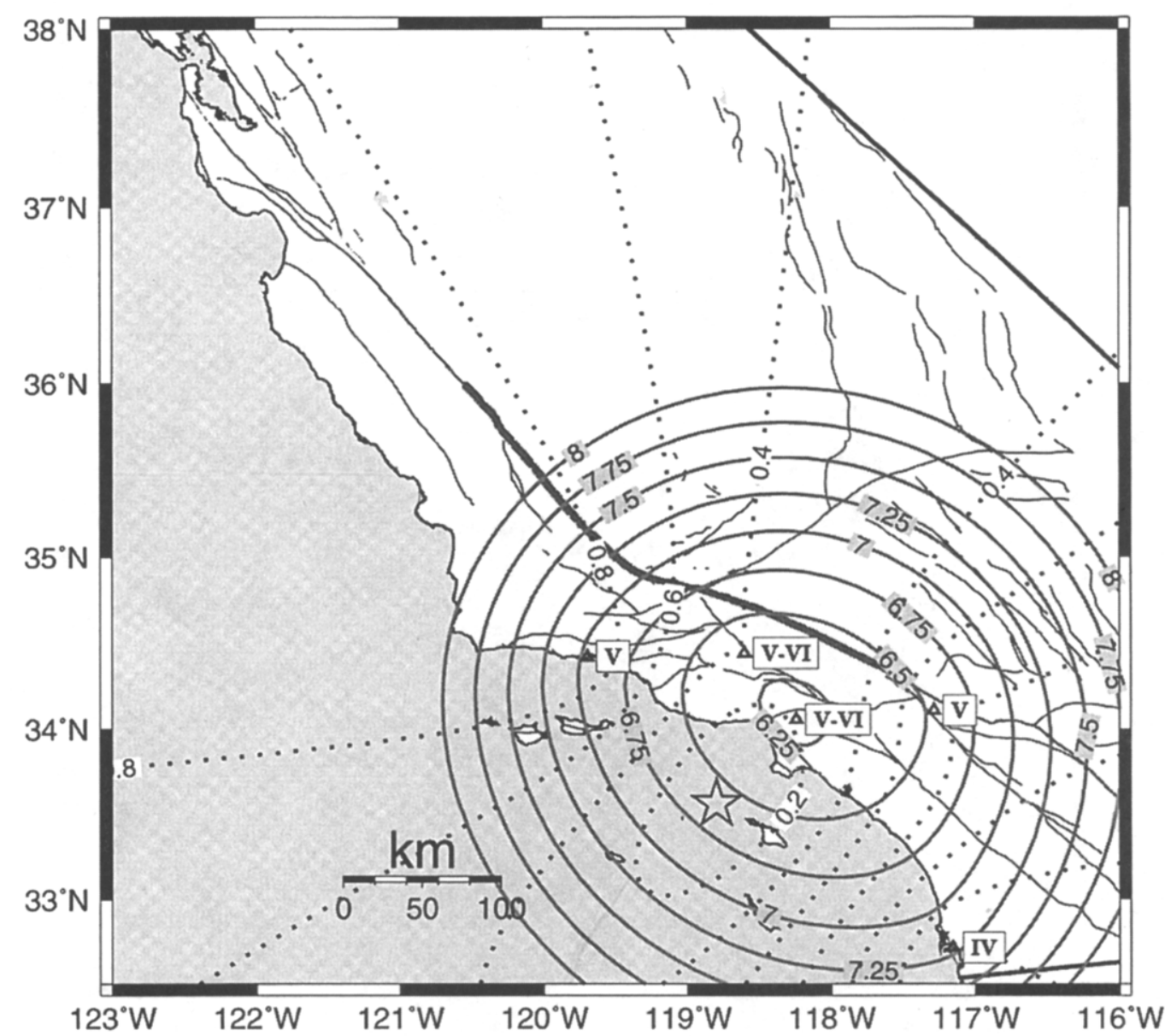

Figure 5. Map of rms contours and magnitude contours for the 16 January 1857 , afternoon aftershock. Thin lines are faults; the thick line is the extent of the 1857 rupture; triangles are stations with intensity data (possible MMI values are indicated in roman numerals); dotted contours are rms contours; the clear star is the location corresponding to the intensity center; and the solid contours are magnitude contours. See text for details.

certainty (as noted in roman numerals on Fig. 2) has very little impact on the results: the contour shapes remain elongated, and the point of least rms on the SAF ranges from 30 to $45 \mathrm{~km}$ northwest of Parkfield. In Figure 2, the magnitude is approximately 6.1 along this stretch of fault, but alternative MMI selections allow the magnitude to wander between 6.0 and 6.3. This event was not reported, however, by a reliable observer 15-20 miles northwest of San Benito, which leads us to believe that a magnitude of 6.3 is too high (Sieh, 1978b). (MMI I, or "not felt," is not handled by the algorithm of Bakun and Wentworth.) The most tectonically attractive location within the region of low rms error is the $\mathrm{SAF}$, considering that the mainshock originated on that or a nearby stretch of that fault only two hours later. Using rms error contours, we constrain the location to a stretch of the SAF from $\sim 10$ to $\sim 60 \mathrm{~km}$ northwest of Parkfield. Considering error in magnitude arising solely from uncertainty in intensities, we assign a magnitude of $M 6.1 \pm 0.1$; yet we must also allow for uncertainty in magnitude, as determined in Table 2 and as discussed earlier in this article. We add an additional error of \pm 0.2 for uncertainty in magnitude to the error resulting from uncertainty in intensities, yielding a magnitude (and overall error) of $M 6.1 \pm 0.3$ (50\% confidence) for the dawn foreshock. The location for this earthquake is consistent with the results of Sieh (1978b), and this magnitude is at the upper end of the range he determined.

\section{Sunrise Foreshock}

The analysis of the sunrise foreshock is more of a challenge because many of the primary reports upon which we would need to rely for data for this foreshock are ambiguous and unreliable, and based on our analysis, this earthquake was considerably smaller than the dawn foreshock. We have only three locations with reliable reports of an earthquake felt at about sunrise: three reports from San Francisco, one by the observer 15-20 miles northwest of San Benito, and 


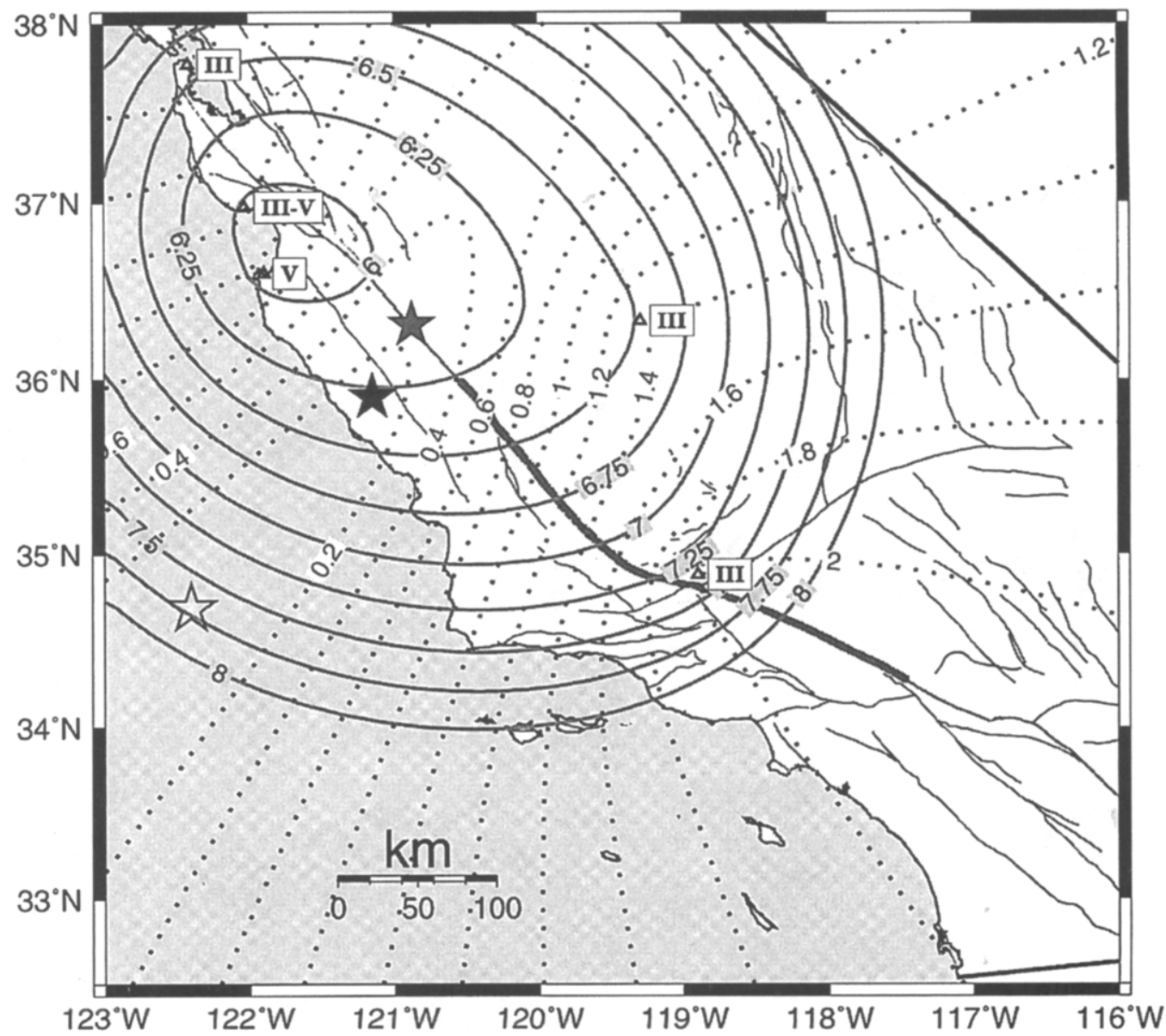

Figure 6. Map of rms contours and magnitude contours for the 16 April 1860 aftershock. Thin lines are faults; the thick line is the extent of the 1857 rupture; triangles are stations with intensity data (possible MMI values are indicated in roman numerals); dotted contours are rms contours; the clear star is the location corresponding to the intensity center; the shaded (filled) star is the location of the least rms value among points on the SAF; the black (solidly filled) star is the location of the least rms value among points on the Nacimiento Fault; and the solid contours are magnitude contours. See text for details.

Table 1

Confidence Parameters: Location of Epicentral Region

\begin{tabular}{cccccc}
\hline & \multicolumn{5}{c}{ rms $\left[M_{i}\right]$ Contour } \\
\cline { 2 - 6 } \# of MMI & $95 \%$ & $90 \%$ & $80 \%$ & $67 \%$ & $50 \%$ \\
\hline 5 & 0.484 & 0.392 & 0.285 & 0.206 & 0.136 \\
7 & 0.372 & 0.295 & 0.214 & 0.150 & 0.098 \\
10 & 0.287 & 0.228 & 0.161 & 0.114 & 0.072 \\
15 & 0.214 & 0.168 & 0.122 & 0.086 & 0.054 \\
20 & 0.175 & 0.140 & 0.102 & 0.072 & 0.046 \\
25 & 0.154 & 0.122 & 0.089 & 0.064 & 0.041 \\
30 & 0.139 & 0.111 & 0.082 & 0.058 & 0.038 \\
\hline
\end{tabular}

Figures from W. Bakun (written communication, 1999). See the Appendix for further discussion of these parameters.
Table 2

Confidence Parameters: Magnitude

\begin{tabular}{rccccc}
\hline & \multicolumn{5}{c}{ Limits } \\
\cline { 2 - 5 } \# of $M M I$ & $95 \%$ & $90 \%$ & $80 \%$ & $67 \%$ & $50 \%$ \\
\hline 3 & $-0.71,0.56$ & $-0.57,0.47$ & $-0.42,0.37$ & $-0.30,0.29$ & $-0.20,0.20$ \\
5 & $-0.58,0.45$ & $-0.47,0.38$ & $-0.35,0.30$ & $-0.25,0.23$ & $-0.16,0.17$ \\
7 & $-0.50,0.39$ & $-0.41,0.33$ & $-0.31,0.26$ & $-0.23,0.21$ & $-0.15,0.15$ \\
10 & $-0.45,0.35$ & $-0.37,0.29$ & $-0.29,0.24$ & $-0.21,0.18$ & $-0.14,0.13$ \\
15 & $-0.39,0.30$ & $-0.34,0.26$ & $-0.26,0.21$ & $-0.20,0.17$ & $-0.13,0.12$ \\
20 & $-0.36,0.27$ & $-0.31,0.24$ & $-0.25,0.19$ & $-0.19,0.16$ & $-0.13,0.12$ \\
25 & $-0.35,0.26$ & $-0.29,0.22$ & $-0.24,0.18$ & $-0.19,0.15$ & $-0.13,0.11$ \\
30 & $-0.33,0.24$ & $-0.29,0.21$ & $-0.24,0.17$ & $-0.19,0.14$ & $-0.13,0.11$
\end{tabular}

Figures from Bakun and Wentworth (1999).

See the Appendix for further discussion of these parameters. 


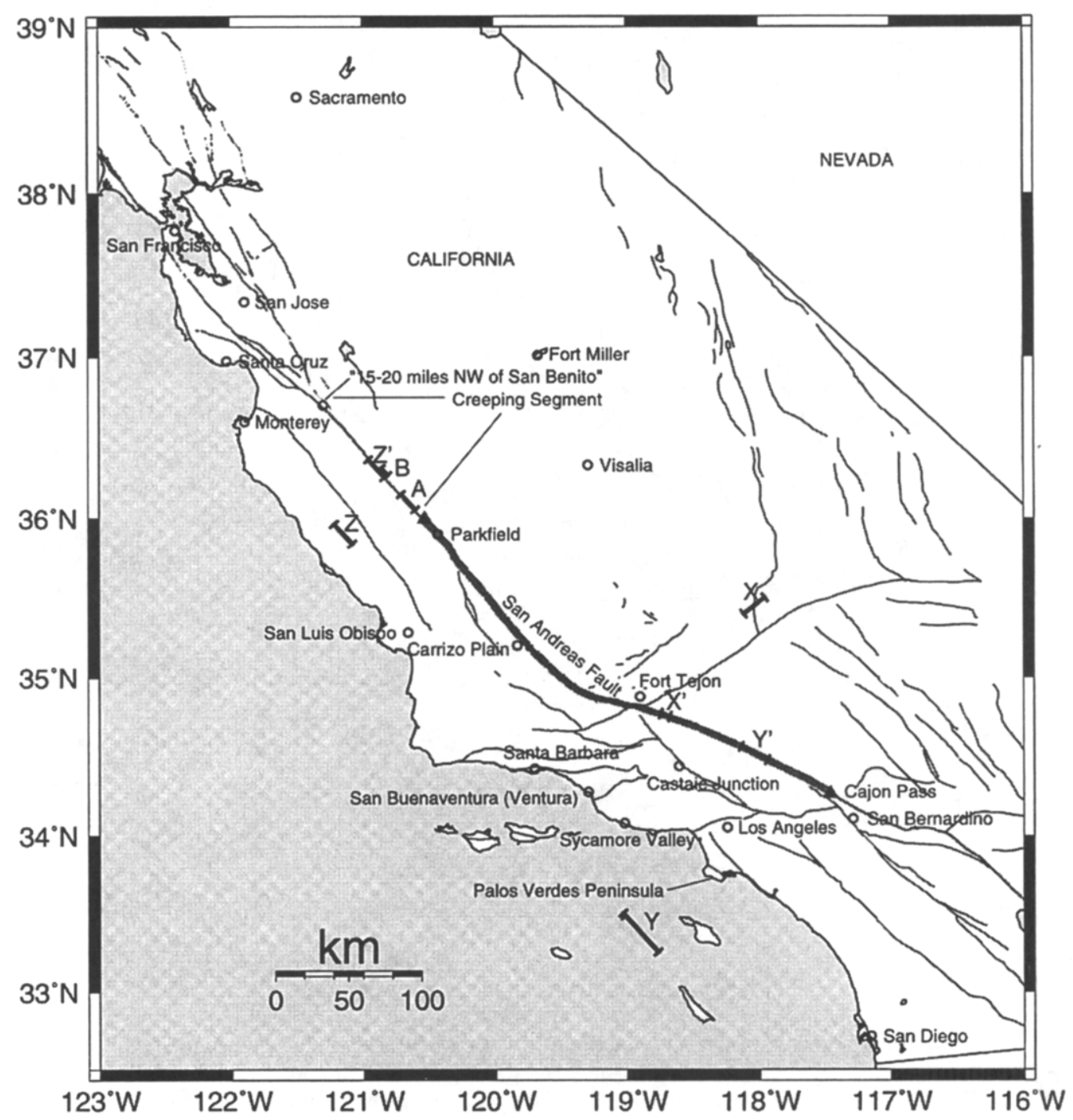

Figure 7. Summary map showing the best locations for the foreshocks and aftershocks plotted in Figures 2-6. The bars represent empirical strike-slip rupture lengths appropriate for the event's magnitude, based on data from Wells and Coppersmith (1994), and are oriented according to the dominant local fault trend. The letters correspond as follows: A, best location for the dawn foreshock, which is assumed to be on the SAF; B, best location for the sunrise foreshock, which is assumed to be on the SAF; X, best unconstrained location for the 9 January aftershock; $X^{\prime}$, best location for the 9 January aftershock, when constrained to the SAF; Y, best unconstrained location for the 16 January aftershock; $Y^{\prime}$, best location for the 16 January aftershock, when constrained to the SAF; Z, best unconstrained location for the April 1860 aftershock; and $Z^{\prime}$, best location for the April 1860 aftershock, when constrained to the SAF. Coordinates and magnitudes for these points are given in Table 3 . This figure does not include the 16 December 1858 event in the San Bernardino region.

one from Visalia (Meltzner and Wald, 1988). It is not even clear that this was one moderately sized event as opposed to two or three local events. We estimate an appropriate magnitude and location if indeed it was a single earthquake, but we emphasize that there is no concrete evidence that mandates a single-event hypothesis.

For the sunrise foreshock, the algorithm identifies a region of low rms error within an elongated set of contours stretching south-southwest to north-northeast and intersect- ing the SAF northwest of Parkfield (Fig. 3). The intensity center is in the eastern Central Valley, although this location is unlikely, since the earthquake was not recorded in the Meteorological Records at nearby Fort Miller (only a foreshock at 2:30 a.m. and the mainshock were recorded there; see Meltzner and Wald, 1988, p. 96). We plotted alternate maps for this event (not shown; see Meltzner and Wald, 1998, Fig. 4B) incorporating four observations we considered not to be fully reliable, in addition to the observations 
noted in Figure 3. If we consider all of the maps and then constrain the location to the SAF, the result is a stretch of fault $\sim 10$ to $\sim 100 \mathrm{~km}$ northwest of Parkfield. The magnitude range from these maps is $M 5.6 \pm 0.1$, although factoring in uncertainty in magnitude according to Table 2 gives us $M 5.6 \pm 0.3$ (50\% confidence). This region of the SAF is characterized historically by creep, although recent work by Toppozada and Borchardt (1998) indicates the occurrence of a $M \approx 5.25$ event along this portion of the SAF in 1855 (see Fig. 1). If we assume that the observations used in this analysis all describe the same earthquake, our results are consistent with those of Sieh. Note, however, that Sieh made these very assumptions in his own work.

\section{Largest Aftershocks}

\section{January 1857 (Night) Aftershock}

Between 22:27 and 22:53 PST on the night of 9 January, one particularly strong earthquake was reported in a number of localities in southern California and in Visalia (Tulare County). (Keep in mind that in 1857, timing was often imprecise and inaccurate; for the mainshock, quite a few reports were off by more than an hour.) The best fits to the observed intensities (see Fig. 4 for an example of a particular choice of the assumed intensities) point to a location in the mountains northwest of the Garlock fault, in a region bounded roughly by California State Highways 14, 58, and 178; the fault involved may have been the Garlock or Sierra Nevada fault, or any of a number of smaller faults. Estimated magnitude is $M 6.25 \pm 0.5$ (50\% confidence), considering both sources of error discussed earlier. No portion of the SAF is included within the $50 \%$ confidence interval in any of the plots for this aftershock.

But reports from the Tejon Indian Reservation are inconsistent with a $M \approx 6.25$ earthquake on or near the Garlock fault. The Tejon Indian Reservation, $20 \mathrm{~km}$ northeast to east-northeast of FT, at the mouth of Tejon Canyon in the Tehachapi Mountains, would have been the closest observation point to the intensity center, and one would expect the intensity there to be $\mathrm{V}$ or greater; yet in the daily journal of the Tejon Indian Reservation, only "ten slight shocks during the day" following the mainshock are noted for 9 January (Meltzner and Wald, 1988, p. 86), suggesting that nothing was felt with intensity greater than III or IV. We must remember that numerous aftershocks were felt over much of California in the hours following the mainshock, and it is possible that some of the reports used to obtain a location in the vicinity of the Garlock fault might be describing separate events. (Contrarily, we cannot assume that every shock at Tejon Reservation was recorded or that, following the MMI VII-VIII shaking experienced during the mainshock that morning, the reporter would bother describing an earthquake with MMI V-VI; in other words, our concern here might be unfounded.) We therefore propose a $M 6.25 \pm 0.5$ event on or northwest of the Garlock fault, although we cannot be certain the event was quite that large or quite in that Iocation.
If, for argument's sake, we constrain the location to the SAF, the magnitude would be $M 5.6 \pm 0.4$. Alternatively, a scenario of two earthquakes at separate locations, each of $5 \leq$ $M \leqslant 6$, could explain the observations.

\section{January 1857 (Afternoon) Aftershock}

On the afternoon of 16 January another significant aftershock occurred, which was felt in much of southern California, from San Diego to San Bernardino to Santa Barbara. The rms error contours again point to a source off the SAF (see Fig. 5 for an example), although this time it is offshore. The intensity center ranges in the plots from 40 to $80 \mathrm{~km}$ southwest of the Palos Verdes Peninsula, and the 50\% confidence interval $(0.136 \mathrm{rms}$ contour $)$ in each plot is a broad ellipse, elongated in a southwesterly direction as a consequence of being unbounded offshore. The SAF lies outside the $50 \%$ confidence interval on all of the maps for this event, although the coastal areas of the Los Angeles Basin lie within the $50 \%$ confidence interval in one map, that shown in Figure 5. In the region of the intensity center on each map, the magnitude is within $M 6.7 \pm 0.3$, and accounting for magnitude uncertainty yields $M 6.7 \pm 0.5$ (50\% confidence); however, if we again constrain the location to the SAF, the magnitude would be $M 6.3 \pm 0.3$ (50\% confidence, accounting for both sources of error).

\section{5-16 December 1858 Aftershocks}

Two significant events were felt near San Bernardino on the night of 15 December 1858 and the early morning of 16 December. They were felt most strongly at San Bernardino (modified Mercalli intensities V-VI and VII, for the 15 and 16 December events, respectively), although they were also felt sharply at Los Angeles (intensities IV and IV-V). Ellsworth (1990) estimates $M \approx 6$ for the 16 December event. Unfortunately, we were unable to plot a map for either of these events, since we need a minimum of three intensity data points (at three separate localities) for the map to be of any use. Nevertheless, we can reasonably conclude that it was the strongest earthquake in the San Bernardino region in the years following the 9 January 1857 mainshock.

\section{April 1860 Aftershock}

The singular notable aftershock to occur along the northern extent of the rupture took place on 16 April 1860. In general, it appears to have been a repetition of the foreshocks near Parkfield, having been felt from FT to Visalia to San Francisco. A solution for one particular choice of the assumed intensities is shown in Figure 6 . The intensity center is offshore, roughly $170 \mathrm{~km}$ west-southwest of San Luis Obispo, but again the rms contours are highly elongated perpendicular to the SAF, and the offshore location of the intensity center results more from a lack of offshore data points than from any other factor. A "Bryson" location on the Nacimiento fault (again, see Fig. 1 for location) is possible, since the location falls on or near the boundary of the $50 \%$ confidence interval, but a Coalinga location and locations on the SAF fail to fall within that interval. Nevertheless, a com- 
parison of intensities in this earthquake with those in the dawn and sunrise foreshocks and in modern Parkfield events leaves open the possibility of an event on the SAF. The main difference for the 1860 aftershock is the lack of reporting sources from Santa Barbara, the Carrizo Plain, and northwest of San Benito. The Nacimiento fault location corresponds to $M 6.3 \pm 0.3$ (50\% confidence, accounting for both sources of error discussed in this article); similarly, if we constrain the location to the SAF, the associated magnitude would be $M 6.2 \pm 0.3$ (50\% confidence, again accounting for both sources of error). Both the Nacimiento fault and the SAF locations are shown on Fig. 6.

\section{Duration of the Aftershock Sequence}

The 1857 rupture segment of the SAF has a very low level of background seismicity, and that opens the question as to whether the duration of the aftershock sequence of the 1857 mainshock would be comparable to the duration of aftershock sequences of modern earthquakes on smaller faults in California. Because the seismic record is more complete at FT for January 1857 through May 1861 than at other locations along the fault, we focus on this record. If we assume that the rate of seismicity at FT before 1857 equaled the contemporary rate (which we define as the background rate), we can determine a lower bound for the duration of the FT aftershock sequence.

To determine the contemporary, or background, rate, we searched through the Southern California Earthquake Center (SCEC) Data Center's earthquake hypocenter database, which at the time of analysis, was complete for events recorded by the Southern California Seismic Network (SCSN) between 1 August 1983 and the present. We restricted the search to the 10-yr period 1 January $198400 \mathrm{hr} 00 \mathrm{~min} 00$ sec to 31 December $199323 \mathrm{hr} 59 \mathrm{~min} 59 \mathrm{sec}$ to avoid inflation of the seismicity rate by aftershocks of the 17 January 1994 Northridge, California earthquake. We then searched for earthquakes of $M \geq 2.5$ in a box bounded by latitudes $33^{\circ}$ and $37^{\circ} \mathrm{N}$ and by longitudes $121^{\circ}$ and $117^{\circ} \mathrm{W}$. For the resulting set of over 3000 events, we calculated the peak ground acceleration (PGA) predicted for FT $\left(34.88{ }^{\circ} \mathrm{N}\right.$ latitude, $118.90^{\circ} \mathrm{W}$ longitude) using a regression for peak acceleration as a function of magnitude and distance (Joyner and Boore, 1981) modified for smaller events (H. Kanamori, written communication, 1998). Finally, we associated PGA values with modified Mercalli intensities, and we tried to determine how many earthquakes could be felt at FT in a typical year of background seismicity.

For the 10-yr period 1984-1993, an average of 0.5 events/yr generated a PGA at FT greater than or equal to $1.4 \% \mathrm{~g}\left(13.7 \mathrm{~cm} / \mathrm{sec}^{2}\right)$, which is the lower bound of MMI IV (Wald et al., 1999); an average of 1.7 events/yr generated a PGA greater than or equal to $0.7 \% \mathrm{~g}\left(6.9 \mathrm{~cm} / \mathrm{sec}^{2}\right)$, which is near or below the lower bound of MMI III (this bound is poorly constrained); and an average of 9.4 events per year generated a PGA greater than or equal to $0.17 \% \mathrm{~g}(1.67 \mathrm{~cm} /$ $\sec ^{2}$ ), which is the lower bound of MMI II (Wald et al.,
1999). Hence, in an average year, FT will experience shaking of $\mathrm{MMI} \geq \mathrm{IV} 0.5$ times, shaking of MMI $\geq \mathrm{III} 1.7$ or fewer times, and shaking of $\mathrm{MMI} \geq \mathrm{II} 9.4$ times.

Examining the Meteorological Records and Monthly Reports (sources 21 and 22, respectively, in Meltzner and Wald, 1998, Appendix 2) from FT from January 1857 through May 1861, we see that earthquakes were repeatedly described using the words "slight," "severe," "heavy," "very severe," or "very heavy," and were occasionally described as "barely perceptible," "scarcely perceptible," "very slight," or "extremely heavy." Any earthquake that was felt and recorded, unless described as "very slight" or as "barely" or "scarcely perceptible," was probably felt with MMI III or greater; any earthquake described as "severe" or "heavy" was almost certainly felt with MMI $\geq I V$. Looking through the Meteorological Records and Monthly Reports for January 1857 to November 1859 , it is apparent that the rate at which earthquakes were felt at FT during this period was well above the background seismicity rate for the region. Specifically, for the 9-month period from March to November 1859,17 distinct earthquakes were recorded at FT, none of which should be assumed to have had an intensity below III; and 4 events were described as either "severe" or "heavy," and should be considered to have been felt with MMI IV or greater. The equivalent annual rate for this ninemonth period is 22.7 events of MMI III or greater, and 5.3 events of MMI IV or greater-a 10-fold increase over background seismicity rates determined above. (Keep in mind that the rates for 1859 are minimums, since not all felt earthquakes were necessarily recorded.)

There was a period from December 1859 to March 1860 when no earthquakes were recorded, but looking at records from April to September 1860, we again find elevated seismicity rates: in that 6-month period, 5 earthquakes were felt and recorded at FT, none of which had an intensity below III, and at least 1 of which had MMI IV or greater. The equivalent annual rate for this period is 10 events of $\mathrm{MMI}$ III or greater, and 2 events of MMI IV or greater (although it may be a little presumptuous to determine a rate based on one event); again, this is above the background seismicity rate. After September 1860, no earthquakes were recorded, although it is unclear whether that was because no more earthquakes were felt, or simply because felt earthquakes were no longer being recorded. Regardless, historical records from FT indicate that seismicity levels remained elevated above the background rate through at least September 1860 , from which we can conclude that the aftershock sequence of the 1857 earthquake continued for a minimum of 3.75 years.

\section{Size, Number, and Rate of Decay of Aftershocks}

Another question arises as to whether the size and number of aftershocks of a large earthquake on the SAF are proportional to the size and number of aftershocks of modern earthquakes on smaller faults. The magnitudes of aftershocks generally follow a Gutenberg-Richter relation, with 
each unit decrease in mainshock magnitude leading to a 10fold decrease in the total number of aftershocks (Reasenberg and Jones, 1989). Using the statistics of Reasenberg and Jones, we calculate that in a 5-yr period following a $M 7.9$ mainshock, we would typically expect 1 aftershock of $M \geq$ 6.9 , roughly 4 events of $M \geq 6.4$, and roughly 13 events of $M \geq 5.9$ within the aftershock zone. Yet our data indicate that no aftershocks equaled or exceeded $M 6.9$, and only 1 aftershock exceeded $M 6.4$. We have identified 4 aftershocks that exceeded $M 5.9$, and although we may have missed a few events of $5.9 \leq M \leq 6.4$, it appears that the total number of aftershocks of $M \geq 5.9$ was lower than expected. The observed aftershock sequence for the FT earthquake appears to be marginally smaller than, although not inconsistent with, what would be expected based on statistics of smaller events in California. However, the size of an aftershock zone is poorly defined for an event as large as the FT earthquake, and our small aftershock sequence may result partly from studying an area that is too small.

As a final point, one should note that the FT earthquake aftershock sequence was characterized by slower-than-average decay: only one large aftershock occurred within the first 24-hr period, the largest aftershock occurred more than one week after the mainshock, and several large events occurred more than 23 months into the sequence. (Hough and Jones [1997] noted that out of 13 selected southern California mainshock-aftershock sequences for which the mainshock and the largest aftershock were both over $M$ 5.5, 8 mainshocks were followed by their largest aftershock within $1 \mathrm{hr}$, and all were followed by their largest aftershock within $10 \mathrm{hr}$; in contrast, the 1968 Borrego Mountain earthquake [which was not included in the selected 13] and its largest aftershock were separated by more than 1 yr.) Poor reporting does not appear to be a factor in this apparent lack of other sizable aftershocks early on, since the resolution of earthquake reporting in the hours and days following the mainshock was higher than at any time later in the aftershock sequence. Unless an aftershock occurred before shaking from the mainshock had ended, such that the mainshock and aftershock would be indistinguishable to observers (as in the 1994 Northridge earthquake [Hough and Jones, 1997]), it is extremely unlikely that any large aftershocks $(M \geq 5.9)$ occurred on 9 January and were overlooked.

\section{Conclusions}

The two largest foreshocks were located on or near the Parkfield segment of the SAF and had magnitudes of $M \approx$ 6.1 and $M \approx 5.6$. They preceded the mainshock by 2 and 1 $\mathrm{hr}$, respectively. The aftershocks included two significant events during the first eight days of the sequence, with magnitudes $M \approx 6.25$ and $M \approx 6.7$, near the southern half of the rupture. Later aftershocks included a $M \approx 6$ event near San Bernardino in December 1858 and a $M \approx 6.3$ event near the Parkfield segment in April 1860. Overall, the aftershock rate was below average but within one standard deviation of the number of aftershocks expected based on statistics of modern southern California mainshock-aftershock sequences. We also conclude that the aftershock sequence lasted a minimum of 3.75 years.

Figure 7 is a summary map, showing locations for the two largest foreshocks and the three largest aftershocks. Although analysis of the data suggests that the largest aftershocks occurred off the SAF, we plotted (in addition to the preferred locations) the best-fit locations if we constrained each aftershock to the SAF; the constrained locations should be considered possible, but unlikely, scenarios. For these five events, we determined empirical strike-slip rupture lengths appropriate for each magnitude, based on the moment magnitude-rupture length regression of Wells and Coppersmith (1994), and we represent these rupture lengths on Figure 7, centered at our preferred location. The preferred and constrained coordinates for these events are given in Table 3.

\section{Acknowledgments}

Many people contributed to the completion of this study. We benefited greatly from discussion with or help from William Deverell, Jim O'Donnell, and Kerry Sieh at Caltech; William Bakun and James Dewey of the U.S. Geological Survey; Tousson Toppozada of the California Division of Mines and Geology; and Duncan Agnew at U.C. San Diego. We also thank William Bakun, Lucile Jones, and Paul Reasenberg of the USGS for very useful reviews, which improved this manuscript. Maps in this report have been created using GMT (Wessel and Smith, 1991). This work has been supported with funds provided by the Summer Undergraduate Research Fellowship program of the California Institute of Technology, and by the U.S. Geological Survey.

Table 3

Location and Magnitude of Largest Foreshocks and Aftershocks

\begin{tabular}{|c|c|c|c|c|c|c|}
\hline \multirow[b]{2}{*}{ Event } & \multicolumn{3}{|c|}{ Preferred Version } & \multicolumn{3}{|c|}{ SAF Constrained Version } \\
\hline & Lon $\left({ }^{\circ} W\right)$ & Lat $(N)$ & Magnitude & Lon $\left({ }^{\circ} \mathrm{W}\right)$ & Lat $\left({ }^{\circ} \mathrm{N}\right)$ & Magnitude \\
\hline Dawn FS* & \multicolumn{3}{|c|}{ See SAF constrained version } & 120.65 & 36.10 & $M=6.1 \pm 0.3$ \\
\hline Sunrise FS* & \multicolumn{3}{|c|}{ See SAF constrained version } & 120.85 & 36.29 & $M=5.6 \pm 0.3$ \\
\hline 9 Jan 1857 AS & 118.00 & 35.44 & $M=6.25 \pm 0.5$ & 118.71 & 34.76 & $M=5.6 \pm 0.4$ \\
\hline $16 \mathrm{Jan} 1857 \mathrm{AS}$ & 118.90 & 33.38 & $M=6.7 \pm 0.5$ & 118.04 & 34.52 & $M=6.3 \pm 0.3$ \\
\hline 16 Dec 1858 AS & \multicolumn{2}{|c|}{ Near San Bernardino (?) } & $M=6(?)$ & & & \\
\hline 16 Apr 1860 AS & 121.15 & 35.90 & $M=6.3 \pm 0.3$ & 120.88 & 36.31 & $M=6.2 \pm 0.3$ \\
\hline
\end{tabular}

*Preferred version is on SAF. 


\section{References}

Agnew, D. C., and K. E. Sieh (1978). A documentary study of the felt effects of the great California earthquake of 1857 , Bull. Seism. Soc. Am. 68, 1717-1729.

Bakun, W. H., and C. M. Wentworth (1997). Estimating earthquake location and magnitude from seismic intensity data, Bull. Seism. Soc. Am. 87, 1502-1521.

Bakun, W. H., and C. M. Wentworth (1999). Erratum to "Estimating earthquake location and magnitude from seismic intensity data," Bull. Seism. Soc. Am., 89, 557.

Ellsworth, W. L. (1990). Earthquake history, 1769-1989, in The San Andreas Fault System, California, R. E. Wallace (Editor), U.S. Geol. Surv. Profess. Pap. 1515, 152-187.

Hough, S. E., and L. M. Jones (1997). Aftershocks: are they earthquakes or afterthoughts? Eos 78, 505, 508.

Joyner, W. B., and D. M. Boore (1981). Peak horizontal acceleration and velocity from strong-motion records including records from the 1979 Imperial Valley, California, earthquake, Bull. Seism. Soc. Am. 71, 2011-2038.

Meltzner, A. J., and D. J. Wald (1998). Foreshocks and aftershocks of the great 1857 California carthquake, U.S. Geol. Surv. Open-File Rept. 98-465, $115 \mathrm{pp}$.

Reasenberg, P. A., and L. M. Jones (1989). Earthquake hazard after a mainshock in California, Science 243, 1173-1176.

Richter, C. R. (1969). Possible seismicity of the Nacimiento fault, California, Bull. Geol. Soc. Am. 80, 1363-1366.

Sieh, K. E. (1978a). Slip along the San Andreas fault associated with the great 1857 earthquake, Bull. Seism. Soc. Am. 68, 1421-1448.

Sieh, K. E. (1978b). Central California foreshocks of the great 1857 earthquake, Bull. Seism. Soc. Am. 68, 1731-1749.

Toppozada, T. R., and G. Borchardt (1998). Re-evaluation of the 1836 "Hayward fault" and the 1838 San Andreas fault earthquakes, Bull. Seism. Soc. Am. 88, 140-159.

Wald, D. J., V. Quitoriano, T. H. Heaton, H. Kanamori, and C. W. Scrivner (1999). TriNet "ShakeMaps": rapid generation of peak ground motion and intensity maps for earthquakes in southern California, Earthquake Spectra, (in press).

Wells, D. L., and K. J. Coppersmith (1994). New empirical relationships among magnitude, rupture length, rupture width, rupture area, and surface displacement, Bull. Seism. Soc. Am. 84, 974-1002.

Wessel, P., and W. H. F. Smith (1991). Free software helps map and display data, Eos 72, 441, 445-446.

\section{Appendix}

\section{Appendix: A Discussion on Confidence Parameters}

A few words of explanation are necessary concerning the confidence parameters given in Tables 1 and 2. Bakun and Wentworth (1997) included a distance weighting function both in the algorithm and in the computation of confidence parameters corresponding to various rms error contours. This distance function preferentially weights intensity observations from reporting sources near the epicentral region. This would seem a logical correction, the authors argued, because intensity observations near an assumed epicenter are particularly sensitive to an error in its location, whereas intensity observations farther away are less sensitive. Indeed, comparing the confidence levels corresponding to various rms contours for $60,70,80$, and more observations with and without the distance weighting function (see Meltzner and Wald, 1998, Appendix 4), we see that the weighting function improves the confidence of the rms contours, which in turn means that the determination of location is improved.
However, for smaller numbers of observations-in particular, for 30 or fewer observations (compare Table 1 to data from Bakun and Wentworth [1999])-the opposite holds true: the distance weighting function actually decreases the confidence of the rms contours. It appears that, with very few observations, the distance weighting function biases the determination of epicenter toward a portion of the observation points, when in fact all observation points might be considerably removed from the epicenter. Since there were fewer than 30 observations for each of the earthquakes we studied, we did not use the distance weighting function, either in the OFR or in this paper. In the OFR, we published a table of confidence parameters for location that was valid for the modified algorithm (lacking the distance weighting function), as well as a table of uncertainties in magnitude for various levels of confidence. Note that the uncertainties in magnitude are independent of and unaffected by the distance weighting function. Hence, the confidence parameters for location for the modified algorithm in the OFR (not using the weighting function) differed from the equivalent parameters for the original Bakun and Wentworth algorithm (using the weighting function), although the parameters for uncertainty in magnitude were the same in both papers.

Subsequent to publication of Bakun and Wentworth (1997) and publication of the OFR, Bakun and Wentworth discovered a mistake in their computation of confidence parameters for both location and magnitude; this mistake also affects the values for the modified algorithm published in the OFR. Bakun and Wentworth (1999) have published a correction of the confidence parameters in their previous work (Bakun and Wentworth, 1997); although, as with the earlier article, the correction considers only the original Bakun and Wentworth algorithm, which incorporates the weighting function. Consequently, for the confidence parameters for location, the numbers given by Bakun and Wentworth (1999) are not valid for our modified algorithm, and a special set of corrected parameters needed to be generated. We obtained this set of parameters in a written communication from W. Bakun (1999), and we publish it as Table 1. However, since magnitude uncertainty parameters are indifferent to the distance weighting function, the corrected parameters for magnitude that are given in Bakun and Wentworth (1999) are valid for our modified algorithm, and we reprint them in Table 2 in this article.

Division of Geological and Planetary Sciences

California Institute of Technology

Pasadena, California 91125

E-mail: meltzner@gps.caltech.edu

(A.J.M.)

U.S. Geological Survey

525 S. Wilson Avenue

Pasadena, California, 91106

E-mail: wald@usgs.gov

(A.J.M., D.J.W.) 